\title{
Report of high genetic diversity of filarial worm, Wuchereria bancrofti from endemic region of Eastern Maharashtra (India)
}

\author{
A. L. MAHAKALKAR ${ }^{1}$, H. P. SAPKAL ${ }^{2}$, M. M. BAIG ${ }^{1 *}$
}

'Laboratory of Molecular and Conservaion Genetics, Department of Zoology ,Government Vidarbha Institute of Science and Humanities, Amravati 444604, MS, India, E-mail: mumtazbaig@gmail.com; 2Department of Zoology, Shri Shivaji College of Arts,Commerce and Science, Akola, 444001,MS, India

\section{Article info}

Received November 10, 2016 Accepted June 26, 2017

\begin{abstract}
Summary
"Filariasis free India" is National Health Policy's vision. Currently, India has undertaken Mass Drug Administration drive (MDA) to eliminate the filariasis infection. Taking this into account, the emergence of new Wuchereria bancrofti resistant strains against the current choice of drugs cannot be ruled out. In this study, we report the genetic diversity of Wuchereria bancrofti from four districts (Amravati, Nagpur, Chandrapur and Wardha) of Vidarbha, a region in the eastern part of Maharashtra state of India and considered a hot spot of filariasis infections. The RAPD profiles were generated for 21 populations using nine random RAPD primers. The RAPD- PCR based distance matrix shows maximum genetic distance of 0.425 between the parasites from Nagpur and Amravati region and minimum genetic distance of 0.210 between the parasites of Wardha and Nagpur. The tree inferred by Neighbour-Joining (NJ) method shows four distinct clusters. With the single exception of isolates from Amravati, all other clusters show the intermingling of isolates with other districts. Further, the representation of isolates from Chandrapur in three out of four clusters revealed to be a founder and indicates towards the entry of the filarial worm into the Maharashtra state through southern route. Keywords: Genetic diversity; Wuchereria bancrofti; Lymphatic filariasis; RAPD - PCR; Vidarbha
\end{abstract}

\section{Introduction}

Lymphatic filariasis, more frequently referred as elephantiasis is a vector-borne parasitic disease caused by three lymph dwelling nematode parasites viz., Wuchereria bancrofti, Brugia malayi and Brugia timori (Pani et al., 1994; WHO 1992). Worldwide, 120 million people in 80 countries are infected with filarial parasites, and alarming number of about 1.2 billion people are at risk of acquiring infection. Neverthless, one-third of the infected population lives in India, and an equal number in Africa, the remaining population in Asia, Pacific regions and in South and North America (WHO 1997). Globally, filariasis is spread by different species of mosquitoes like Culex, Aedes, Mansonia and Anopheles (Sasa 1976). In
India, $W$. bancrofti is solely transmitted by Culex quinquifqsciatus mosquitoes while, B.malayi is transmitted by the Mansonia (Das et al., 2002., Sabesan et al., 1992).

Genetic diversity study divides the Indian $W$. bancrofti population into two major strains, the Eastern and the Western, falling on the either sides of the Western Ghat range (Patra et al., 2007; Thangadurai et al., 2006). A pilot study attempted in South India demonstrated considerable genetic variation in the $W$. bancrofti population (Pradeep Kumar et al., 2002). Similarly, a higher genetic variation using RAPD marker has been reported in the diurnal $W$. bancrofti population of Andaman and Nicobar Islands (Dhamodharan et al., 2011). In the Maharashtra state of India, the disease is endemic to 17 districts (Thane, Sindudurg, Solapur, Os-

\footnotetext{
* - corresponding author
} 


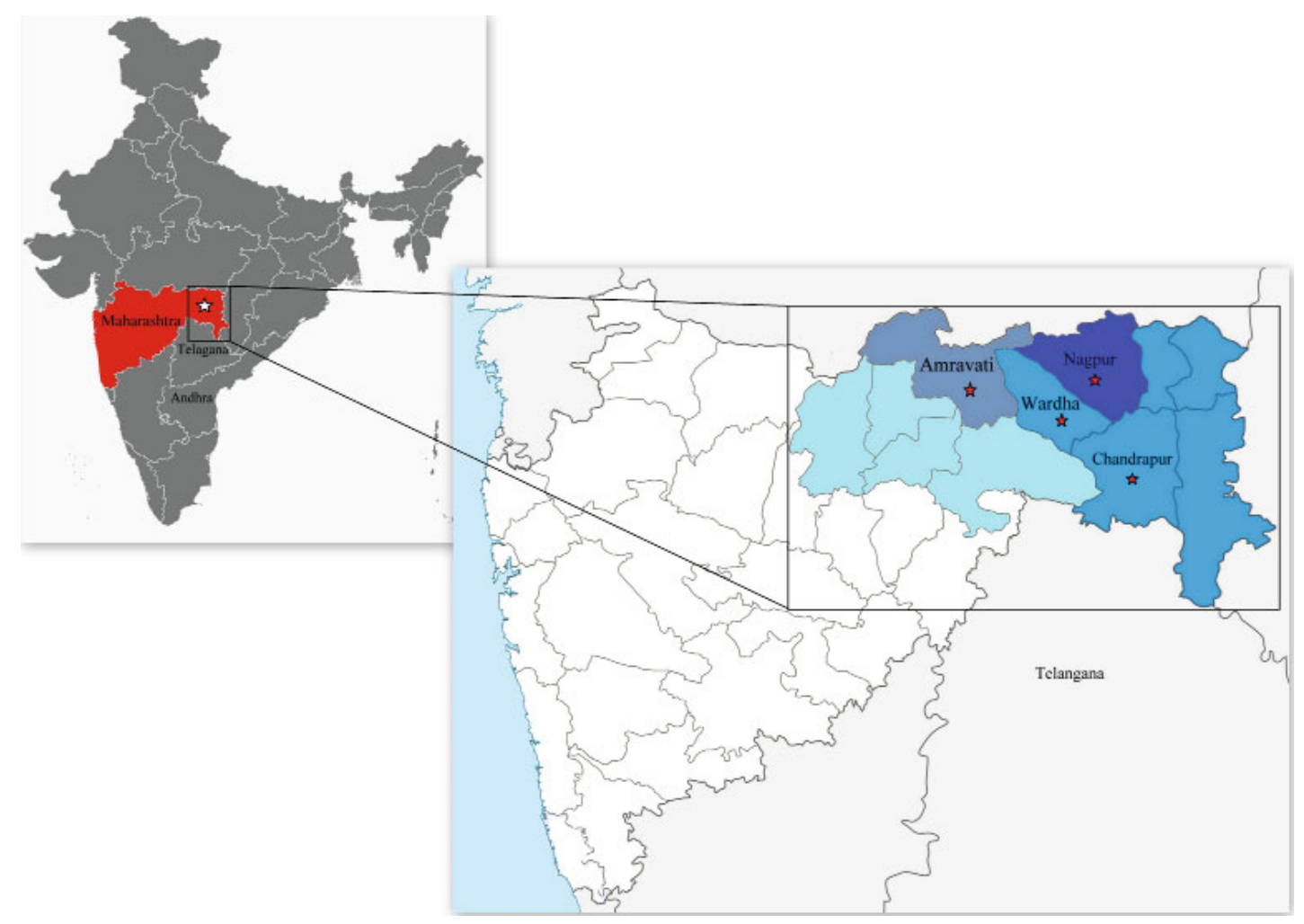

Fig. 1. Map of India showing the position of Eastern Maharashtra (Vidarbha) endemic districts were sampling was carried out is denoted by "그"

manabad, Latur, Nanded, Nandurbar, Jalgaon, Yevatmal, Akola, Amravati, Nagpur, Wardha, Bhandara, Gondia, Chandrapur, Gadchiroli, http://arogya.maharashtra.gov.in). Notably, out of these 17 districts, nine districts alone lie in the Vidarbha region of Maharashtra (Fig. 1). Thus, making Vidarbha or Eastern Maharashtra a hot spot of $W$. bancrofti infections and an important region to be focused on in the national eradication program. Global Program for the Elimination of Lymphatic Filariasis (GPELF) employs the Mass Drug Administration (MDA) method and uses Albendazole, DEC or Ivermectin as choice of drugs to reduce the load of circulating microfilariae ( $\mathrm{mf}$ ) below a threshold level to prevent their further transmission by the infected vectors. Now, India is witnessing the MDA approach to eliminate the elephantiasis. Considering this scenario, the possibility of emergence of a new W. bancrofti strains against the preferred choice of certain drugs persists. Unavalibility of whole genome sequence information of $W$. bancrofti and difficulty in obtaining tiny parasite material for study, makes RAPD the preferred method for a genetic diversity study. Though few studies previously include samples from this hot-spot of lymphatic filariasis, but no comprehensive study to unravel the genetic diversity of filarial parasites has been attempted from this region. This study attempted to test the hypothesis that enormous genetic diversiy lies in the endemic region and understanding this diversity is an urgent need to eradicate the worm, to make India filariasis free as envisaged by the National health policy's vision.

\section{Materials and Methods}

\section{Study area}

Vidarbha is the name assigned to the eastern part of the Indian state of Maharashtra. Vidarbha comprises $31.6 \%$ of total area of the state and constitutes $21.3 \%$ of total state population. Out of nine Vidarbha endemic districts four were included in this study. To be exact, the districts included were Amravati, Nagpur, Chandrapur and Wardha (Fig. 1). The Amravati is a district of Maharashtra state in the Vidarbha region of central India, while Nagpur is located at the exact centre of the Indian peninsula and lies on the Deccan plateau. Chandrapur is a district in the Nagpur division, located at the border of Andhra Pradesh, and outlines the eastern part of the Vidharbha region. The district is adjacent to the Nagpur, Bhandara and Wardha on the northern side. Gadchiroli is located on the eastern side and Adilibad district of the Andhra Pradesh on the southern side. Wardha district belongs to the Maharashtra state of western India and is located within the Nagpur division.

\section{Sample collection}

Microfilaria (mf) of W.bancrofti were collected on glass slides from different endemic regions of Vidarbha, Amravati ( Walgaon, Shirala, Talvel and Nandgaon villages ), Nagpur (Khairi pannase, Metaumri), Chandrapur and Wardha (Karanja, Seloo, Devwadi). 
All sample collections were carried out with assistance and supervision of the District Filarial Survey Unit.

Table 1. List of decamer primers used for RAPD-PCR.

\begin{tabular}{ccc}
\hline Primers & Sequence 5' $^{\prime}$ to 3' $^{\prime}$ & \% of GC content \\
\hline OPA 1 & CAGGCCCTTC & $70 \%$ \\
OPA 2 & TGCCGAGCTG & $70 \%$ \\
OPA 3 & AGTCAGCCAC & $60 \%$ \\
OPA 4 & AATCGGGCTG & $70 \%$ \\
OPA 9 & GTGGTCCGCA & $70 \%$ \\
OPA 16 & AAGCGACCTG & $60 \%$ \\
\hline
\end{tabular}

\section{Microfilaria collection and DNA extraction}

This study followed the protocol of Dhamodharan et al., (2011) with a few modifications. The Mf positive slides were first focused at 10X magnification, and then after the determination of the Mf position, lysis buffer containing $1 \mathrm{M}$ Tris- $\mathrm{HCL}(\mathrm{pH}-8), 5 \mathrm{M} \mathrm{NaCl}$, $10 \% \mathrm{SDS}, 0.5 \mathrm{M}$ EDTA, Proteinase $\mathrm{K}(2 \mathrm{mg} / \mathrm{ml})$ and water were added. As the material on the slide became soluble, the mf was picked up with the help of single hair of fine brush and washed in Phosphate Buffer Saline (PBS). Collected Mf was subsequently transferred in the water and later placed into the lysis buffer for the DNA extraction. Using this method, at least five Mf from each individual slide were collected and pooled. Genomic DNA was extracted using DNA extraction kit (GENETIX Miniprep Kit GENETIX, Rome, GA). After extraction, DNA was stored at $-20{ }^{\circ} \mathrm{C}$.

\section{RAPD-PCR}

For a RAPD-PCR, $30 \mu \mathrm{L}$ reaction mixture was prepared. The mixture includes a PCR super mix (Fermentas, USA), 10x buffer,
1.5 units Taq, RAPD primer (Bioserve), W.bancrofti DNA template and water. The 40 cycle reaction was set up which includes initial denaturation at $96{ }^{\circ} \mathrm{C}$ for $4 \mathrm{~min}$; followed by 40 cycles of $94^{\circ} \mathrm{C}$ for $1 \mathrm{~min}$, annealing at $40^{\circ} \mathrm{C}$ for $1 \mathrm{~min}$, and extension at $72^{\circ} \mathrm{C}$ for $2 \mathrm{~min}$. Finally, the amplicons were extended at $72{ }^{\circ} \mathrm{C}$ for $7 \mathrm{~min}$

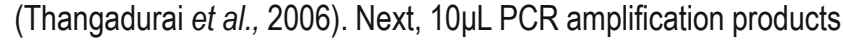
with $2 \mu \mathrm{L}$ DNA loading dye were separated on $2 \%$ Agarose gel containing Ethidium bromide at $100 \mathrm{~V}$ for three hours using $1 \mathrm{x}$ TBE buffer. The gel was viewed under Kodak Gel Logic 212 Imaging System and was photographed for further analysis, samples were screened by nine decamer oligonucleotides (Operon technology, USA) (Table 1).

\section{Data analysis}

Of the nine oligonucletide decamers only six oligonucleotides, yielded polymorphic bands. The scored data of each primer was combined into a single binary matrix using MESQUITE software (Maddison et al., 2007). Based on the RAPD data, a genetic distance of 21 samples was calculated using MEGA 4 evolutionary software (Tamura et al., 2007) using method described by Tajima and Nei (1984). The NEXUS file obtained through MESQUITE was used to construct Neighbour-Joining (NJ) phylogenetic tree method using PAUP 4.0 software (Swofford, 2003).

\section{Results}

Polymorphic bands resulted from amplification of total 21 samples of $W$. bancrofti by OPA I, OPA 2, OPA 3, OPA 4, OPA 9, OPA 16 primers are depicted on Table 2. The size ranged from 210 to 1500 base pairs and the obtained band patterns are compared with $1 \mathrm{~kb}$ DNA marker (Thermo Scientific Gene Ruler, Fig 2).

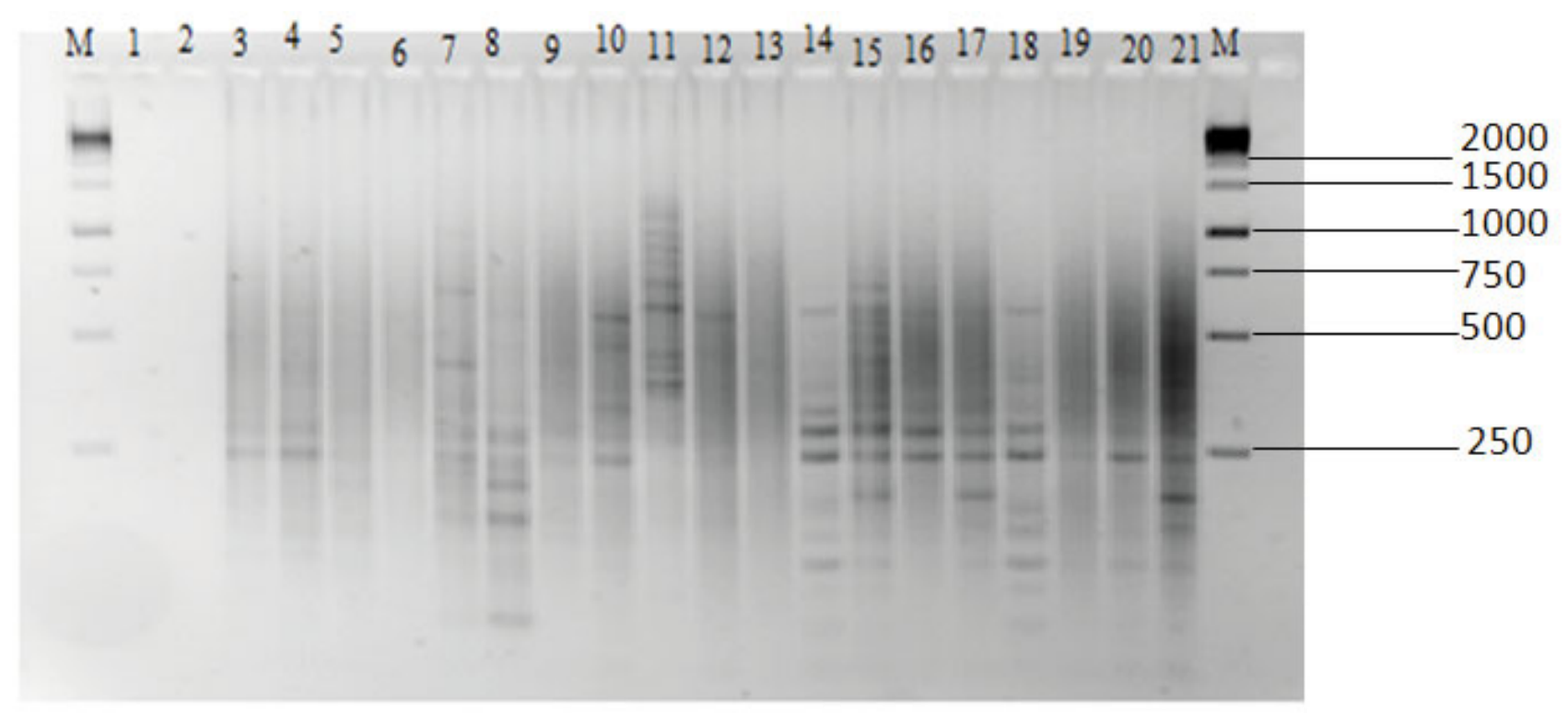

Fig. 2. RAPD-PCR screening by OPA 16 primers of $W$. bancrofti isolates (lane-1 to 8 Amravati, lane- 9 to 13 Chandrapur, lane-14 to 19 Nagpur and lane 20 and 21 Wardha),M- DNA Marker. 
Table 2. Scorable DNA bands generated by six random operon primers through RAPD-PCR.

\begin{tabular}{cccccc}
\hline Sr. No. & Area(Districts) & $\begin{array}{c}\text { Number of } \\
\text { samples }\end{array}$ & $\begin{array}{c}\text { Total no. of } \\
\text { bands produced }\end{array}$ & $\begin{array}{c}\text { No. of Polymorphic } \\
\text { bands }\end{array}$ & $\begin{array}{c}\text { Percent of } \\
\text { Polymorphism }\end{array}$ \\
\hline 1 & Amravati & 08 & 197 & 39 & 19.79 \\
2 & Chandrapur & 05 & 109 & 38 & 34.86 \\
3 & Nagpur & 06 & 136 & 24 & 17.64 \\
4 & Wardha & 02 & 46 & 06 & 13.04 \\
Pooled & & 21 & 488 & 107 & 21.92 \\
Average & & 5.25 & 122 & 26.75 & \\
\hline
\end{tabular}

\section{Genetic distance analyses}

Genetic distance is generally utilized to study the genetic divergence between species and subspecies. The smaller the genetic distance, the closer is the genetic relationship, whereas the larger the genetic distance, the more distant is the genetic relationship. The RAPD-PCR based distance matrix shows, a maximum genetic distance of 0.425 in between the isolates of Nagpur and Amravati while the minimum genetic distance of 0.210 was found between the isolates of Wardha and Nagpur (Table 3).

Table 3. Genetic distance computed using Tajima-Nei model is shown below the diagonal. Standard error estimate(s) are shown above the diagonal.

\begin{tabular}{lcccc}
\hline & Amravati & Chandrapur & Nagpur & Wardha \\
\hline Amravati & & 0.102 & 0.128 & 0.115 \\
Chandrapur & 0.361 & & 0.056 & 0.093 \\
Nagpur & 0.425 & 0.195 & & 0.059 \\
Wardha & 0.358 & 0.310 & 0.210 & \\
\hline
\end{tabular}

Phylogenetic analysis

Phylogenetic tree construction originating from RAPD-PCR band scoring was one of the main objectives to study the relatedness among $W$. bancrofti isolates. Taking into account the endemic nature of parasite, the tree obtained by NJ method shows region-specific clustering (Fig. 3). Isolates screened from all the districts fall under four distinct clades. The isolates from Amravati district cluster separately. Whereas isolates from Wardha, Nagpur and Chandrapur did not show district specific clustering. The isolates from Chandrapur were found clustering in three out of four clades. The low bootstrap value was either due to unequal and fewer isolates or due to the limitations of RAPD markers.

\section{Discussion}

This study is the first attempt to unravel the genetic diversity of filarial worms, from the Eastern Maharashtra, one of the hot spots of elephantiasis in India, using RAPD-PCR markers. Earlier, Kumar and Patra (2002) studied genetic variation of 21 samples of $W$. bancrofti from South India using 10 random RAPD markers. Outside India, by same RAPD-PCR technique, Surang Nuchprayoon (2007) characterized the genetic differences between the Thai and
Myanmar strains of W.bancrofti and demonstrated the effectiveness of the technique in genetic diversity study of filarial worm.

Despite importance of population genetics of $W$. bancrofti in control strategy, this parasitic nematode have not attain required attention (Thangadurai et al., 2006). The NJ tree constructed using isolates from Eastern Maharashtra show four distinct clusters. Importanatly, with the exception to isolates from Amravati district, all other isolates from Wardha, Nagpur and Chandrapur districts exhibit mixing. Correspondingly, a study by Thangadurai and Hoti (2006) exhibits that the phylogeography of $W$. bancrofti population of different climatic regions of India is complex and has a high degree of divergence and gene flow among populations. The occurrence of isolates from Chandrapur in all four clusters suggests its ancestral position. This corroborates with their entry through the southern route, keeping in mind the proximitity of Chandrapur to the neighbouring southern Indian states of Telangana or Andhra Pradesh. Also, the high genetic diversity found in the isolates from Nagpur district might be due to the cosmopolitan nature of the city which witnesses large scale human movement from surrounding endemic districts and states. Moreover, it is well documented that bancroftian filariasis has moved around the world more by the mass migrations of its human host. Sufficient numbers of infected human hosts had to migrate in order for the parasite to overcome the difficulties of establishing new infections in new geographic regions (Laurence, 1989). Similar genetic heterogeneity of $W$. bancrofti populations from Pondichery and surrounding areas of South India was reported by Hoti and Thangadurai (2008). Their studies also revealed high heterogenicity of $W$. bancrofti in urban population, compared to the rural, induced mainly by the movement of people from the countryside to cosmopolitan cities for the employment. In future, probing genetic diversity by covering a large geographical area, larger sample size and use of high range molecular markers like Sanger sequencing and next generation sequencing would provide more data on the diversity of filarial worms in this endemic region of India.

\section{Conclusion}

Using RAPD-PCR, our study demonstrates high genetic diversity associated with the lymphatic filaria isolates from the eastern 


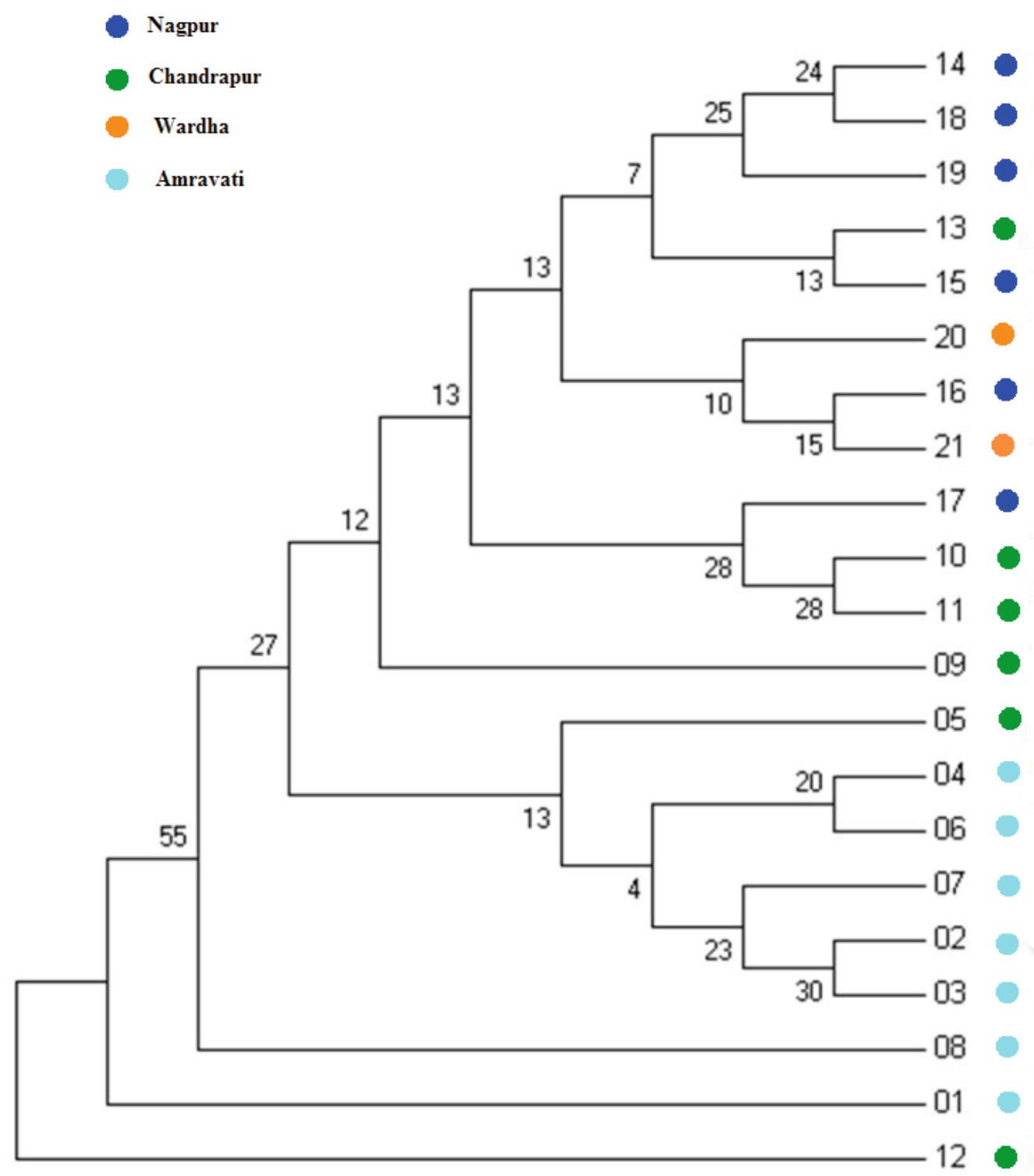

Fig. 3. Phylogenetic tree based on Neighbour joining (NJ) method constructed from isolates collected from four endemic districts in Eastern Maharashtra analysed with the PAUP software.

region of Maharashtra and suggests South India as the most probable entry point for the filarial worm into the Maharashtra state of India.

\section{Acknowledgements}

A. L. Mahakalkar is thankful to VCRC, Pondichery for providing training in molecular techniques related to Filariasis and to the UGC for financial assistance under Post Doctoral Fellowship for Women. All authors are thankful to the National Filaria Control Unit
(NFCU) Amravati, and survey units of Akola, Nagpur, Chandrapur for providing microfilaria positive slides.

\section{References}

DAs, P.K., PANI, S.P. (2002): Filariasis in India: Epidemiology and control. In: Sood, M.L. (Ed) Helminthology in India. International Book Distributors, Dehradun, India

Dhamodharan, R., Hoti, S.L., Rohit, S., Manoj Kumar, D. (2011): Influence of anti-filarial chemotherapy strategies on the ge- 
netic structure of Wuchereria bancrofti populations. Mem. Inst. Oswaldo Cruz., 106(2): 240 - 247. DOI: 10.1590/S007402762011000200020

Government of Maharashtra Public Health Department (2017): http://arogya.maharashtra.gov.in

Hoti, S.L., Thangadural, R., Dhamodharan, R., Das, P.K. (2008): Genetic heterogeneity of Wuchereria bancrofti populations at spatially hierarchial levels in Pondicherry and surrounding areas, south India. Infect. Genet. Evol., 8: 644 - 652. DOI: 10.1016/j. meegid.2008.06.002

LAURENCE, B.R. (1989): The global dispersal of bancroftian filariasis. Parasitol. Today, 5: 260 - 265. DOI: 10.1016/01694758(89)90260-3

Maddison, W.P., Maddison, D.R.( 2007): Mesquite: A modular system for Evolutionary analysis, version 2.6. Available online at: http://mesquiteproject.org

PANI, S.P, Dhanda, V. (1994): Natural history and dynamics of progression of clinical manifestation of filariasis. In: Kumar, S., SEN, A.K., Dutta, G.P., Sharma, R.N. (Eds) Tropical Disease: Molecular Biology and Control Strategies. Publication and Information Directorate, CSIR, New-Delhi, pp. 1 - 8

Pradeep Kumar, N., Patra, K.P., Hotı, S.L., Das, P.K. (2002): Genetic variability of the human filarial parasite, Wuchereria bancrofti in South India. Acta Trop., 82: 67 - 76. DOI: 10.1016/S0001706X(02)00037-2

Sabesan, S., Palaniyandi, M., Das, P.K., Michael, E. (2000): Mapping of lymphatic filariasis in India. Ann. Trop. Med. Parasitol., 94 (6): 591 - 606. DOI: 10.1080/00034983.2000.11813582

Sabesan, S., Pradeep Kumar, N., Krishnamoorthy, K., Panicker, K.N. (1992): Seasonal abundance and biting behaviour of Mansonia annulifera, Mansonia uniformis and Mansonia Indiana and their relative role in the transmission of Malayan filariasis in Shertallai (Kerala State). Indian J. Med. Res., 93: 253.

SASA, M. (1976): Human Filariasis: A Global Survey of Epidemiology and Control. University of Tokyo Press, Tokyo, 336 pp.

SuRAng, N., Alias, J., Yong, P. (2007): Random Amplified Polymorphic DNA (RAPD) for differentiation between Thai and Myanmar strains of Wuchereria bancrofti. Filaria J., 6: 6. DOI: 10.1186/14752883-6-6

Swofford, D.L. (2003): PAUP. Phylogenetic Analysis Using Parsimony (and other methods). Version 4.0b10. Sunderland, MA, USA: Sinauer Associates.

TAJIMA, F., NeI, M. (1984): Estimation of evolutionary distance between nucleotide sequences. Mol. Biol. Evol., 1: 269 - 285

Tamura, K., Dudley, J., Nei, M., Kumar, S. (2007): MEGA4: Molecular Evolutionary Genetics Analysis (MEGA) software version 4.0. Mol. Biol. Evol., 24: 1596 - 1599. DOI: 10.1093/molbev/msm092

Thangadural, R., Hoti, S.L., Pradeep Kumar, N., Das, P.K. (2006): Phylogeography of human lymphatic filarial parasite, Wuchereria bancrofti in India. Acta Trop., 98:(3) 297 - 304. DOI: 10.1016/j. actatropica.2006.06.004

VINOD, S. (2011): Emergence of filariasis in Nanded region (MS) India. Sci. Res. Rep., 1(3): 126 - 131

WHO (1997): Lymphatic filariasis: elimination of a public health problem in our lifetime. Geneva: World Health Organization. Report Number WHO/CTD/FIL/97.4. 20 pp.

WHO (2005): Sixth meeting of the Technical Advisory Group on the Global Elimination of Lymphatic Filariasis, Geneva, Switzerland. Wkly. Epidemiol. Rec., 80: 401 - 408

WHO (1992): Lymphatic filariasis: The disease and its control. Fifth Report of the WHO Expert Committee on Filariasis. World Health Organ. Tech. Rep. Ser., 82: 1 